\title{
CR1 genotype and haplotype involvement in coronary artery disease: The pivotal role of hypertension and dyslipidemia
}

\author{
CHIARA BOIOCCHI ${ }^{1}$, MICHELE ZORZETTO $^{2}$, ILARIA SBARSI $^{3}$, ALESSANDRO PIROTTA $^{4}$, \\ SANDRA SCHIRINZI ${ }^{3}$, COLOMBA FALCONE $^{1,5}$ and MARIACLARA CUCCIA ${ }^{4}$ \\ ${ }^{1}$ Interdepartmental Center for Research in Molecular Medicine (CIRMC), ${ }^{2}$ Laboratory of Biochemistry and Genetics, \\ Institute for Respiratory Disease, Foundation IRCCS Policlinico San Matteo, ${ }^{3}$ Immunogenetics Laboratory, \\ Immunohaematology and Transfusional Medicine Centre, Foundation IRCCS Policlinico San Matteo, \\ ${ }^{4}$ Laboratory of Immunogenetics, Department of Genetics and Microbiology, University of Pavia, Pavia; \\ ${ }^{5}$ Department of Cardiology, Istituto di Cura Città di Pavia University Hospital, Pavia, Italy
}

Received December 29, 2008; Accepted February 24, 2009

DOI: 10.3892/ijmm_00000221

\begin{abstract}
Inflammation plays a pivotal role in the pathogenesis of atherosclerosis and coronary syndromes. Atherosclerosis is a complex multifactorial disorder. Data indicate that the complement proteins play a crucial role in the link between inflammation and atherogenesis. Thus, there is evidence supporting the role of complement activation in atherogenesis. Complement receptor 1 (CR1) is a membrane protein found on different cells involved in various activities of the complement system. We demonstrated the possible involvement of CR1 in atherosclerosis studying the allele and genotype frequencies of the CR1 Pro1827Arg, CR1 His1208Arg exon 22 and int27 HindIII polymorphisms in a sample of patients with angiographically documented coronary artery disease $(C A D)(n=550)$ and in healthy controls $(n=380)$ matched for age, gender and ethnicity. Our data showed no significant deviations between the two groups with regard to either allele or genotype frequencies. After stratification according to risk factors, our analysis revealed a reduced frequency of the GG genotype of the Pro1827Arg polymorphism in patients with CAD and dyslipidemia vs the controls $(p=0.031)$ and of the GG and LL genotypes in CAD patients with dyslipidemia vs CAD patients without dyslipidemia regarding the Pro1827Arg and CR1 HindIII intron 27 polymorphisms (GG, p=0.019; LL, $\mathrm{p}=0,184)$. We analyzed the haplotype frequencies of CR1. A decrease in CAD patients carrying the CAC haplotype compared to controls ( $\mathrm{p}=0.043$ ) and a decrease in the CAC haplotype in CAD patients with hypertension vs healthy controls $(\mathrm{p}=0,029)$ were demonstrated.
\end{abstract}

Correspondence to: Dr Chiara Boiocchi, CIRMC, University of Pavia, Viale Taramelli 24, 27100 Pavia, Italy

E-mail: chiara.b@ipvgen.unipv.it

Key words: hypertension, inflammation, atherosclerosis, coronary artery disease, CR1 genetics
Our data showed a possible involvement of CR 1 gene polymorphisms in the predisposition to the development of this disease.

\section{Introduction}

Atherosclerosis is a progressive disease characterized by accumulation of lipids and fibrous elements in large arteries. It constitutes the single most important contributor to the growing burden of cardiovascular disease. In particular, it is the primary cause of coronary artery disease (CAD) and stroke (1). Epidemiological studies have revealed numerous risk factors for atherosclerosis. These can be grouped into factors with an important genetic component, and those which are largely environmental (2). Atherosclerosis, formerly considered a lipid storage disease, is now known to involve an ongoing inflammatory response $(3,4)$. Recent advances in basic science have established a fundamental role for innate immunity and inflammation in mediating all stages of the disease, from initiation to progression and, ultimately, to thrombotic complications.

Emerging data strongly underline that complement activation is an important link between inflammation and atherogenesis $(5,6)$. While most current models of atherogenesis consider oxidation to be the decisive modifying event in atherogenesis (7), evidence demonstrates that modification of tissue-entrapped low-density lipoprotein (LDL) is an essential factor, since it enables the lipoprotein to signal the immune system and to affect its own removal.

The first step in this process is LDL modification which occurs through the action of hydrolytic enzymes. Then enzymatically remodelled LDL binds C-reactive protein (CRP) $(8,9)$ and activates complement in a number of ways. Simultaneously, epitopes are exposed to enable the lipoprotein to be recognized and taken up by macrophages. These physiological processes occur throughout life without harm, pathologically evolving only when the machinery suffers overload. Detrimental effects are then evoked primarily by activation of complement, macrophages, and other effectors of the immune system in atherosclerotic lesions (9). 
The complement system comprises approximately 35 components which participate in the defense against microbes, in the generation of inflammatory reactions in tissues, and in the clean-up and repair of tissues. Complement can be activated via three separate pathways (10): the classic pathway of activation by immunoglobulins and CRP; the lectin pathway of activation by bacterial mannose-binding lectin; and the alternative pathway of activation by 'foreign' surfaces. Earlier findings supporting the role of complement activation in atherogenesis showed that although no significant complement activation takes place in normal arteries, complement is extensively activated in atherosclerotic lesions and it is particularly evident in vulnerable and ruptured plaques. In atherosclerotic lesions, complement is reportedly activated via the classic and alternative pathways: both immunohistochemical staining and quantitative analysis of lesion extracts have shown the retention and activation of $\mathrm{C} 1 \mathrm{q}, \mathrm{C} 4, \mathrm{C} 3$ and generation of the terminal membrane attack complex C5b-9 in lesions (11). In light of these observations highlighting the significance of complement molecules in atherosclerosis and CAD, we focused on complement receptor 1 (CR1) and its polymorphisms in order to ascertain whether it plays a role in CAD and atherosclerosis. Complement receptor 1 (CR1, CD35, C3b/C4b receptor) codified by a gene located on chromosome $1 \mathrm{q} 32$ is a membrane protein found in different cells, including erythrocytes, phagocytes, all B and some T cells and dendritic cells (12). It is involved in different activities of the complement system (13). In particular, erythrocyte CR1 mediates the transport of ICs throughout the bloodstream to phagocytes in the liver and spleen, and it has been proposed that the rate of IC clearance from the circulation can be directly correlated to the number of CR1 molecules expressed on erythrocytes (CR1/E ratio) (14). Proteolytic cleavage may be responsible for loss of CR1 on the cell surface (15), but quantitative expression of CR 1 on erythrocytes is also genetically determined (16). The CR1 structure is characterized by short consensus repeats (SCRs) of 65-70 amino acids with a conserved core of 11-14 amino acids. In the extracellular domain, 7 SCRs constitute a long homologous repeat (LHR). Four LHRs (LHR-A, -B, -C and -D) are followed by two additional SCRs, a single transmembrane domain, and a COOH-terminal cytoplasmic domain of 43 amino acids. Three additional structural allotypes of CR1 have been found with three, five, or six LHRs, respectively (16).

Several single nucleotide polymorphisms have been found in the CR1 gene (17). In the present study, we focused on three polymorphisms: His1208Arg, intron 27 HindIII RFLP, and Pro1827Arg. His1208Arg results from an $A \rightarrow G$ substitution occurring in exon 22 at nt 3,650. The intron 27 HindIII RFLP gives rise to two alleles: the $\mathrm{H}$ allele, associated with allotypes containing three, four or five LHRs, and the L allele, reported only in association with the allotype containing four LHRs (16). Pro1827Arg results from a $C \rightarrow G$ substitution occurring in exon 33 at nt 5,507. The Pro1827Arg $\mathrm{C}$ allele and the His1208Arg A allele have been reported to be associated with the intron 27 HindIII RFLP H allele, whereas the Pro1827Arg G allele and the His1208Arg G allele have been associated with the intron 27 HindIII RFLP L allele in Caucasians $(16,17)$. The alleles are correlated respectively
Table I. General characteristics and traditional vascular risk factors of the CAD patients $(n=550)$.

Characteristic

\begin{tabular}{lc}
\hline Age, years & $61.8 \pm 9.4$ \\
Male gender & $79.4 \%$ \\
Body mass index, $\mathrm{kg} / \mathrm{m}^{2}$ & $26.1 \pm 3.2$ \\
Hypertension & $46.9 \%$ \\
Hypercholesterolemia & $76.6 \%$ \\
History of smoking & $73.7 \%$ \\
Family history of coronary events & $56.0 \%$ \\
\hline
\end{tabular}

with either a high $(\mathrm{H})$ or low (L) CR1/E ratio $(16,18)$. Erythrocytes from individuals homozygous for the $\mathrm{H}$ allele may show as much as a 10 -fold higher $\mathrm{CR} 1 / \mathrm{E}$ ratio than those from individuals homozygous for the L allele; heterozygous individuals have intermediate CR1 expression (17-19). Since impaired clearance of ICs could result in increased tissue damage in a variety of inflammatory and infectious conditions (16), we hypothesized that coronary artery disease, a disease characterized by a strong inflammatory condition with a possible infectious trigger, could be characterized by an altered frequency of CR1 gene alleles.

\section{Materials and methods}

Study population and design. Allelic, genotype and haplotypic frequencies were investigated in 550 consecutive patients undergoing coronary angiography for anginal pain with myocardial ischemia and 380 healthy controls matched for age, gender and ethnic origin.

Risk factors for atherosclerosis included age, body mass index, hypertension, diabetes, hypercholesterolemia, family history of CAD and smoking habits. Hypertension was defined as a seated systolic blood pressure $\geq 140 \mathrm{mmHg}$ and/or diastolic blood pressure $\geq 90 \mathrm{mmHg}$ on at least three occasions, or if such a diagnosis had been made in the past and the patient was treated with anti-hypertensive medications. Diabetes was defined as a fasting blood glucose level $>7.0 \mathrm{mmol} / \mathrm{l}(126 \mathrm{mg} / \mathrm{dl})$, or treatment with dietary modification, oral hypoglycemic agents or insulin at the time of the study. Hypercholesterolemia was defined as a fasting cholesterol $\geq 6.2 \mathrm{mmol} / \mathrm{l}(240 \mathrm{mg} / \mathrm{dl})$ or treatment with lipidlowering medications. The presence of a family history of coronary artery disease was established if any first degree relative had manifested the disease before 60 years of age Smoking was defined as current daily tobacco use. The characteristics of the patients according to selected risk factors for CAD are shown in Table I.

Each subject gave informed consent for catheterization and genotyping, and the study was approved by the Ethics Committee of the Department of Internal Medicine, University of Pavia, Italy.

Coronary angiography. All subjects underwent diagnostic coronary angiography using standard techniques. CAD was 
Table II. Sequence of primers and restriction fragments for the CR1 gene polymorphisms investigated.

\begin{tabular}{llccl}
\hline & \multicolumn{1}{c}{ Primers } & Size (bp) & Enzyme & Fragment (bp) \\
\hline $\begin{array}{llcl}\text { CR1 His1208Arg } \\
\text { (Fig. 1) }\end{array}$ & CR122 F: 5'-TTCACATTGGATAGCCAGAGC-3' & \multirow{2}{*}{682} & RsaI & G: 458, 162, 62 \\
CR1 Pro1827Arg & CR122 R: 5'-CCAGAGGTTAATCTCCCTGGA-3' & & & A: 520, 162 \\
(Fig. 1) & CR1 F: 5'-AAGCGCACAGTCACAGGTCAC-3' & \multirow{2}{*}{305} & HpyCH4III & C: 296,9 \\
CR1 intron 27 HindIII & CR1 R: 5'-GAACAGAAAGTTCACAGCGAGG-3' & & & G: $242,54,9$ \\
(Fig. 1) & CR127 F: 5'-CAGCAGAGCCAACTTCTGACCC-3' & \multirow{2}{*}{1700} & HindIII & H: 1700 \\
& CR127 R: 5'-CCCTTGTAAGGCAAGTCTGG-3' & & & L: 1200,500 \\
\hline
\end{tabular}

Table III. Frequencies of the CR1 Pro1827Arg (exon 33), CR1 His1208Arg (exon 22) and CR1 intron 27 HindIII polymorphisms in CAD subjects and healthy controls.

\begin{tabular}{lccc}
\hline Polymorphism & Healthy controls & CAD patients & P-value \\
\hline CR1 Pro1827Arg & $\mathrm{n}=386$ & $\mathrm{n}=554$ & \\
CC & $246(64)$ & $365(66)$ & 0.4958 \\
CG & $123(32)$ & $173(31)$ & 0.8359 \\
GG & $17(4)$ & $16(3)$ & 0.2140 \\
C & $615(80)$ & $903(81)$ & 0.3208 \\
G & $157(20)$ & $205(19)$ & 0.3208 \\
CR1 His1208Arg & $n=385$ & $n=515$ & \\
AA & $236(61)$ & $312(60.5)$ & 0.8276 \\
AG & $131(34)$ & $182(35.5)$ & 0.6821 \\
GG & $14(5)$ & $21(4.0)$ & 0.6630 \\
A & $603(78)$ & $806(78.0)$ & 0.9760 \\
G & $167(22)$ & $224(22.0)$ & 0.9760 \\
CR1 intron 27 HindIII & $\mathrm{n}=378$ & $\mathrm{n}=542$ & \\
HH & $236(62)$ & $343(64)$ & 0.4061 \\
HL & $127(34)$ & $181(33)$ & 0.9489 \\
LL & $15(4)$ & $18(3)$ & 0.6035 \\
H & $599(79)$ & $867(80)$ & 0.6945 \\
L & $157(21)$ & $217(20)$ & 0.6945 \\
\hline & & &
\end{tabular}

defined as angiographic evidence of stenosis in any epicardial coronary artery of $\geq 50 \%$ of the diameter. The extent of CAD was defined by the number of major epicardial coronary vessels with angiographic evidence of one or more stenosis of $\geq 50 \%$ severity.

Genetic analysis. Human genomic DNA was obtained from $1 \mathrm{ml}$ of whole blood in EDTA using the GFX Kit (GE Healthcare) following the manufacturer's protocol.

For all polymorphisms investigated, PCR amplifications were carried out in a total volume of $25 \mu \mathrm{l}$ containing $1 \mu \mathrm{l}$ of genomic DNA (final concentration $20 \mathrm{ng} / \mu \mathrm{l}$ ), $0.1 \mu \mathrm{l}$ of Taq polymerase (Eurobio) (final concentration $0.02 \mathrm{U} / \mu 1$ ), $1 \mu 1$ of each primer (final concentration $4 \mathrm{ng} / \mu \mathrm{l}$ ), $2.5 \mu \mathrm{l}$ PCR Buffer 10X (Eurobio), $0.75 \mu 1 \mathrm{MgCl}_{2}$ (Eurobio) (final concentration $1.5 \mathrm{mM}$ ), $2.5 \mu 1 \mathrm{dNTPs}$ (final concentration $2 \mathrm{mM}$ each).
In Table II the sequence of primers and restriction fragments for the CR1 gene polymorphisms investigated are listed. For the CR1 Pro1827Arg C/G exon 33 (rs3811381) and CR1 His1208Arg A/G exon 22 (rs2274567) polymorphisms, amplification was performed using I-Cycler (BioRad) under the following conditions: initial incubation at $95^{\circ} \mathrm{C}$ for $4 \mathrm{~min}$, followed by 5 cycles each of $95^{\circ} \mathrm{C}$ for $15 \mathrm{sec}, 65^{\circ} \mathrm{C}$ for $15 \mathrm{sec}$, $72^{\circ} \mathrm{C}$ for $1 \mathrm{~min} ; 10$ cycles each of $95^{\circ} \mathrm{C}$ for $15 \mathrm{sec}, 60^{\circ} \mathrm{C}$ for $15 \mathrm{sec}, 72^{\circ} \mathrm{C}$ for $1 \mathrm{~min} ; 20$ cycles each of $95^{\circ} \mathrm{C}$ for $15 \mathrm{sec}$, $55^{\circ} \mathrm{C}$ for $15 \mathrm{sec}, 72^{\circ} \mathrm{C}$ for $1 \mathrm{~min}$; final extension was carried out at $72^{\circ} \mathrm{C}$ for $7 \mathrm{~min}$. For the CR1 (C/T 520 AY158532) intron 27 HindIII H/L polymorphism, amplification was performed using the LC480 Thermacycler (Roche) using the following fret probes and primers (Sensor 943-972, Anchor 975-1003, CR1F2 867 and Cr1R2 1066).

Statistical analysis. Data were expressed as means \pm standard deviation. Frequencies of the polymorphisms were compared with the Chi-square test and Fisher's exact test, and differences were considered to be statistically significant at p-values $<0.05$. Hardy-Weinberg equilibrium was assessed by the goodness-of-fit Chi-square test for biallelic markers. Frequencies and haplotype reconstructions were calculated by HPLUS program (http://cougar.fhcrc.org/hplus/).

Linkage disequilibrium was calculated by using JLIN 1.6.0 software (http://www.genepi.org.au/jlin/).

\section{Results}

We focused on the role of complement receptor 1 (CR1) polymorphisms in the inflammatory mechanism involved in the onset and progression of atherosclerosis.

In particular, we evaluated the SNPs located in the CR1 gene (Pro1827Arg exon 33, His1208Arg exon 22 and intron 27 HindIII), determining the polymorphisms described in a set of 550 consecutive patients with angiographically proven CAD and in 380 healthy controls.

All genotypes of the healthy controls and the CAD group agreed with the Hardy-Weinberg equilibrium.

The distribution of CR1 Pro1827Arg exon 33, CR1 His1208Arg exon 22, and CR1 intron 27 HindIII alleles and genotypes in CAD patients and controls are listed in Table III.

Linkage disequilibrium among the three polymorphisms taken two by two was found (D' 22,i27 0.931; D' 22,33 0.955 ; D i27,33 0.964 and respectively $\mathrm{r}^{2} 0.854$; 0.842 ; 0.870) (Fig. 1). 

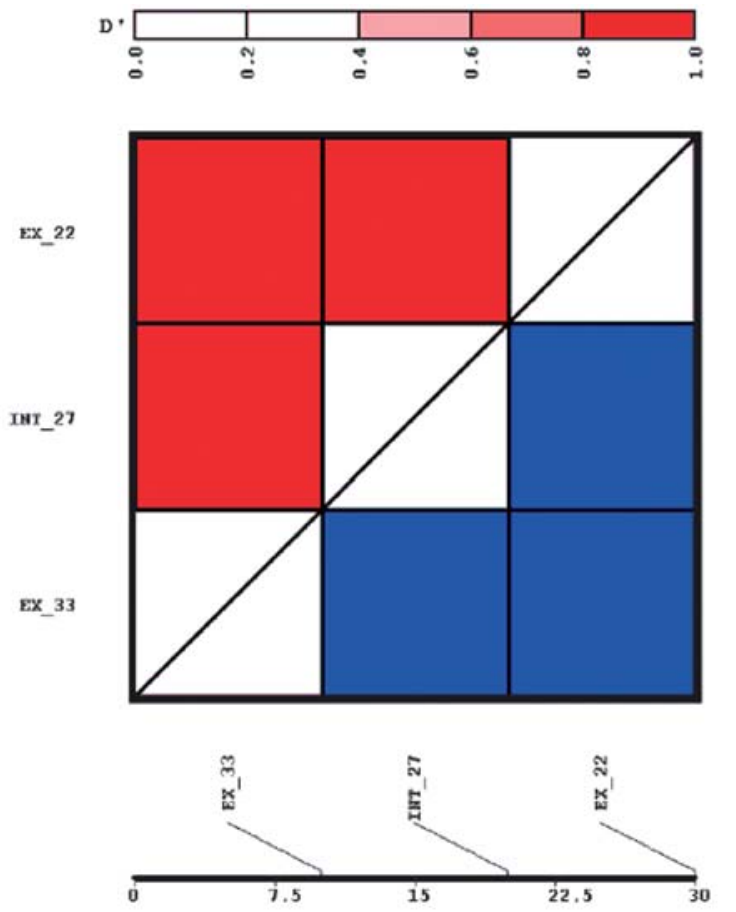

Figure 1. Linkage disequilibrium.

Our data showed no significant deviations between the two groups regarding either allele or genotype frequencies. Considering the role of the complement system and complement receptors in the uptake of LDL by macrophages, our patients were also analyzed in regards to the presence of CAD with dyslipidemia and CAD without dyslipidemia as documented in Table IV and V. Regarding the GG genotype of the Pro1827Arg polymorphism, we found a statistically significant difference comparing CAD patients with dyslipidemia vs. the controls ( $\mathrm{p}=0.031$ ); and GG and LL genotype frequencies were statistically significant in CAD patients with dyslipidemia vs CAD patients without dyslipidemia regarding the Pro1827Arg and CR1 HindIII intron 27 polymorphisms (GG: p=0.019 and LL: p=0.184) (Table V). We analyzed the haplotype frequencies of the CR1 gene. In particular we studied the CAT, GGC, CAC, CGC and CGT haplotypes in our CAD population and in the healthy controls. We found a significant decrease in CAD patients carrying the CAC haplotype compared to controls ( $p=0.043$, Fig. 2). After stratification according to risk factors, our analysis revealed that CAD patients with hypertension displayed statistically significant differences in CAC haplotype frequencies compared with the healthy controls $(\mathrm{p}=0.029)$ as shown in Fig. 3.

\section{Discussion}

Recent evidence demonstrates that atherosclerosis is not simply a lipid deposition disease (20), but is rather an inflammatory process with highly specific cellular and molecular responses $(2,3,9,21)$.

$\mathrm{CAD}$ is a disease with great epidemiological relevance. It is a complex condition resulting from numerous gene interactions, and various genes have previously been studied
Table IV. Frequencies of the CR1 Pro1827Arg (exon 33) polymorphism in CAD subjects with dyslipidemia and healthy controls.

\begin{tabular}{lccc}
\hline Polymorphism & $\begin{array}{c}\text { CAD with } \\
\text { dyslipidemia }\end{array}$ & $\begin{array}{c}\text { Healthy } \\
\text { controls }\end{array}$ & P-value \\
\hline CR1 Pro1827Arg & $\mathrm{n}=236$ & $\mathrm{n}=386$ & \\
CC & $163(69 \%)$ & $264(64 \%)$ & 0.1734 \\
CG & $70(30 \%)$ & $123(32 \%)$ & 0.5641 \\
GG & $\mathbf{3 ( 1 \% )}$ & $\mathbf{1 7}(\mathbf{4 \%})$ & $\mathbf{0 . 0 3 1 0}$ \\
C & $396(84 \%)$ & $615(80 \%)$ & 0.0631 \\
G & $76(16 \%)$ & $157(21 \%)$ & 0.0631 \\
\hline
\end{tabular}

Table V. Frequencies of the CR1 Pro1827Arg (exon 33) and CR1 HindIII intron 27 polymorphisms in CAD subjects with dyslipidemia and CAD subjects without dyslipidemia.

\begin{tabular}{lccc}
\hline Polymorphism & $\begin{array}{c}\text { CAD with } \\
\text { dyslipidemia }\end{array}$ & $\begin{array}{c}\text { CAD without } \\
\text { dyslipidemia }\end{array}$ & P-value \\
\hline CR1 Pro1827Arg & $\mathrm{n}=236$ & $\mathrm{n}=106$ & \\
CC & $163(69 \%)$ & $68(64 \%)$ & 0.3691 \\
CG & $70(30 \%)$ & $32(30 \%)$ & 0.9215 \\
GG & $\mathbf{3}(\mathbf{1 \%})$ & $\mathbf{6}(\mathbf{6 \%})$ & $\mathbf{0 . 0 1 9 0}$ \\
C & $396(84 \%)$ & $168(79 \%)$ & 0.1389 \\
G & $76(16 \%)$ & $44(21 \%)$ & 0.1389 \\
CR1 HindIII intron 27 & $\mathrm{n}=231$ & $\mathrm{n}=105$ & \\
HH & $146(63 \%)$ & $66(63 \%)$ & 0.9514 \\
HL & $81(35 \%)$ & $32(30 \%)$ & 0.4835 \\
LL & $\mathbf{4}(\mathbf{2 \%})$ & $\mathbf{7}(\mathbf{7 \%})$ & $\mathbf{0 . 0 1 8 4}$ \\
H & $373(81 \%)$ & $164(78 \%)$ & 0.4284 \\
L & $88(19 \%)$ & $46(22 \%)$ & 0.4284 \\
\hline
\end{tabular}

(22-24). Inflammation was recently proven to be associated with the pathogenesis of atherosclerosis and its complications (25). Indeed during atherogenesis, characteristic inflammatory cells, proinflammatory cytokines, endothelial adhesion molecules and specific receptors are active (26). CAD can be considered a complex process in which inflammatory molecules play an important role (27). Circulating immune complexes cause inflammation of the vessel wall and accelerate atherosclerosis both in experimental animal models and in humans. Repeated injection of protein antigens leads to the formation of circulating immune complexes and to the acceleration of the spontaneous and diet-induced atherosclerotic process in both rabbits and mice $(28,29)$. Premature atherosclerosis is also observed in patients with chronic immune complex formation due to inflammatory disorders $(30,31)$, and there is an increased incidence of premature myocardial infarction in patients with systemic lupus erythematosus and autoimmune diseases characterized by circulating immune complexes (32). There is also evidence for a link between infection and atherosclerosis, particularly 


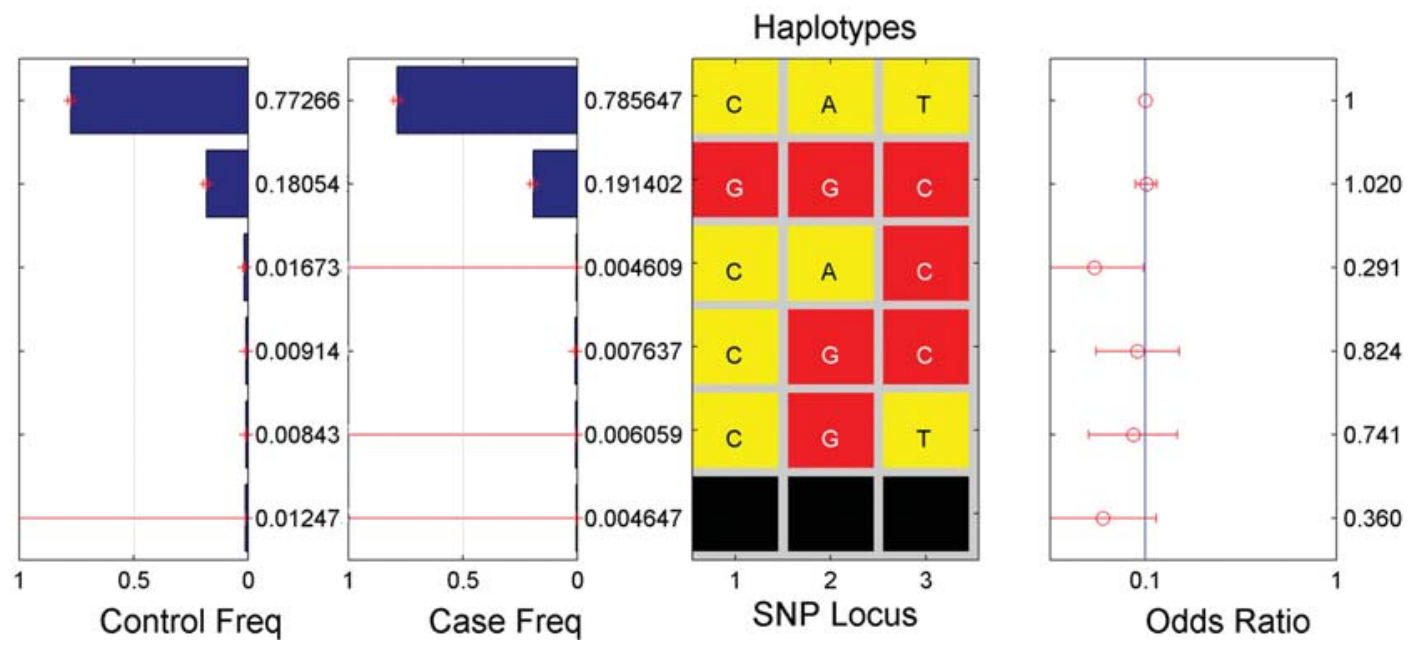

Figure 2. Frequencies of CR1 haplotypes in CAD subjects and healthy controls.

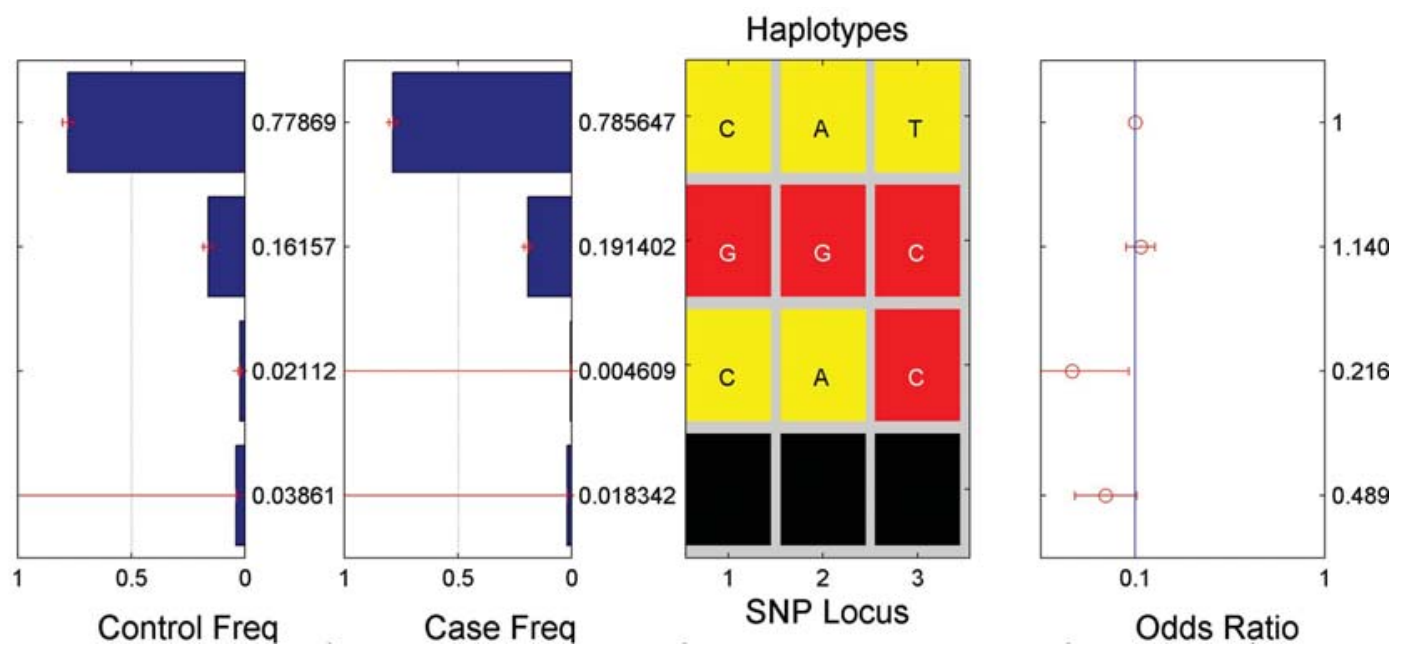

Figure 3. Frequencies of CR1 haplotypes in CAD patients with hypertension and healthy controls.

viral infections (33). Genetic traits contribute significantly to the global risk of atherosclerosis. Accordingly, a number of studies have evaluated the hypothesis that atypical variants of gene coding for proteins such as coagulation proteins (fibrinogen), adhesion molecules (E- and P-selectin), metalloproteinases (MMP-2 and -9) and lipids may increase the risk of disease (34).

One approach to understanding this multifactorial condition is to study disease-correlated genes (35). Association studies with candidate genes provide a powerful approach to identify DNA variants underlying complex cardiovascular traits and are very useful for narrowing a candidate interval identified by linkage analysis. In light of these considerations, gene coding for inflammatory mediators or for molecules involved in the inflammatory mechanism plays a significant role in the risk of developing atherosclerosis. In addition, the genetic polymorphisms of molecules involved in innate immunity may help to understand the increase in the risk of the disease itself (36). These data indicate that the complement system plays a role in the link between inflammation and atherogenesis. Moreover, earlier findings, supporting the role of complement activation in atherogenesis, showed that, although no significant complement activation takes place in normal arteries, complement is extensively activated in atherosclerotic lesions. In addition to the infiltration of complement components from blood plasma, various vascular cells express messenger RNA for complement proteins, and the expression of these proteins is peculiarly up-regulated in atherosclerotic lesions (6). The extent of C5b-9 deposition was found to correlate with the severity of the lesions, and the deposits were primarily found associated with smooth muscle cells, cell debris and extracellular lipids (37). Furthermore, it has previously been observed that the deposition of complement iC $3 \mathrm{~b}$, but not C5b-9, was particularly strong in ruptured and vulnerable plaques, suggesting that complement activation may be a triggering factor in acute coronary syndromes (38). Once a plaque rupture occurs, components of the lesion are released into the bloodstream and may activate the complement system intravascularly (39). Lipids isolated from human atherosclerotic lesions have a high content of unesterified cholesterol and are able to activate the alternative complement 
pathway. Other potential complement activators present in atherosclerotic lesions include cholesterol crystals and cell debris. In light of immunohistochemical and immunoelectron microscopic data, the cell type most susceptible to attack by complement is smooth muscle cell. In particular, the complement cascade, once activated during myocardial ischemia, appears to mediate immune and inflammatory responses in ischemic myocardium (40). Complement activation contributes to myocardial damage through various pathways, including activation of leucocytes and endothelial cells, increase in apoptosis, up-regulation of genes involved in cytokine production and interruption of nitric oxide synthase activity (41). Activation of the complement cascade in patients with myocardial ischemia is evidenced by elevated levels of activated complement by-products, particularly C5a, C5b-9 and $\mathrm{C} 3 \mathrm{a}$ in patient blood and atherosclerotic plaques (6).

CR1 is a membrane protein found in different cells. It is involved in various activities of the complement system. Proteolytic cleavage may be responsible for loss of CR1 on the cell surface; quantitative expression of CR1 on erythrocytes is genetically determined. Several SNPs have been found in the CR1 gene (chromosome 1). It has also been reported that arterial modified LDL was partially uptaken by Fc receptors of macrophages (42) and that complement receptors of macrophages, including CR1, were expressed in atherosclerotic lesions when the complement system was activated. Data suggest that complement receptors may participate in the uptake of LDL by macrophages.

In the present study we investigated the possible association between CAD and CR1 gene polymorphisms in a large group of Italian patients. Our analysis also considered important risk factors for disease susceptibility such as diabetes, hypertension, hypercholesterolemia, age, body mass index, family history of CAD and smoking habits.

We studied the allele and genotype frequencies of the CR1 polymorphisms in our sample of patients $(n=550)$ with angiographically documented CAD and in healthy controls $(n=380)$. Our data do not show an association between CR1 polymorphisms (Pro1827Arg exon 33, His1208Arg exon 22 and CR1 intron 27 HindIII) and CAD susceptibility. After stratification, however, our analysis revealed that CAD patients with dyslipidemia displayed a lower frequency of the GG genotype of the CR1 Pro1827Arg polymorphism than the healthy controls, and this result was confirmed subsequently when we calculated the genotype frequencies in CAD patients with dyslipidemia vs CAD patients without dyslipidemia.

The Pro1827Arg $\mathrm{C}$ allele has been reported to be associated with the intron 27 HindIII RFLP H allele, whereas the Pro1827Arg G allele has been associated with the intron 27 HindIII RFLP L allele in Caucasians $(16,43)$. These alleles are correlated respectively with either a high $(\mathrm{H})$ or low (L) CR1/E ratio. Our data highlight that the frequency of the LL genotype is statistically significantly reduced in CAD patients with dyslipidemia vs CAD patients without dyslipidemia.

These data indicate a possible involvement of this polymorphism in CAD predisposition in these particular pathological settings. In particular, this receptor should be involved not only in the inflammatory component of the atherosclerotic mechanism, in particular in the clearance of
ICs and in the competition with $\mathrm{C} 3$ convertase for $\mathrm{C} 3$ cleavage, but probably in another crucial stage of atherosclerosis: macrophage LDL phagocytosis.

We analyzed the haplotypic frequencies of CR1 in CAD patients and in healthy controls. In this part of the study we demonstrated a significant association between atypical CR1 haplotypes and the severity of CAD, which has never been previously documented. In our sample of Caucasian Italian CAD patients, we found that the CAC haplotype was significantly associated with decreased severity of coronary atherosclerosis as assessed by the mean number of significantly diseased vessels. This finding may be in keeping with a protective role of the CAC haplotype toward the development of advanced atherosclerotic lesions.

Hypertension is an important risk factor for atherosclerosis, and in particular it exerts its negative functions in the coronary bed (44). The reduction in the lumen of the coronary arteries by atheromatous plaques reduces myocardial blood flow thereby favoring ischemia. These plaques may eventually break and thus form peripheral emboli or especially thrombi in situ by means of platelet aggregation which is responsible for acute coronary syndromes. The endothelium-dependent vascular relaxation is altered in hypertension. This endothelial dysfunction brings into function numerous mediators such as nitric oxide (NO), prostacyclines, factors acting on the differentiation and the growth of vascular smooth muscle cells or cyclooxygenase-dependent contraction factor. The anomalies in endothelial function explain, in part, the increase in the risk of CAD in hypertension since they favor vasoconstriction, thrombogenesis and the action of proliferative substances (45).

Our data in particular showed a decrease in the frequency of the CAC haplotype in CAD patients with hypertension compared to the healthy controls, thus underlining a probable implication of CR1 also in this particular pathological setting.

An understanding of the role of the CR1 molecule in this complex mechanism is therefore of pivotal significance in order to further develop innovative and suitable medical therapies in the future.

We aim to extensively investigate the imunogenetics of atherosclerosis and coronary artery disease in order to identify additional genes and polymorphisms implicated in the predisposition to the onset and development of this multifactorial disease.

\section{References}

1. Cambien F, Poirier O, Mallet C and Tiret L: Coronary heart disease and genetics in epidemiologist's view. Mol Med Today 3: 197-203, 1997.

2. Lusis AJ: Atherosclerosis. Nature 407: 233-241, 2000.

3. Ross R: Atherosclerosis is an inflammatory disease. Am Heart J 138: S419-S420, 1999.

4. Koenig W: Inflammation and coronary heart disease: an overview. Cardiol Rev 9: 31-35, 2001.

5. Haskard DO, Boyle JJ and Mason JC: The role of complement in atherosclerosis. Curr Opin Lipidol 19: 478-482, 2008.

6. Oksjoki R, Kovanen PT, Meri S and Pentikainen MO: Function and regulation of the complement system in cardiovascular diseases. Front Biosci 12: 4696-4708, 2007.

7. Leitinger $\mathrm{N}$ : The role of phospholipid oxidation products in inflammatory and autoimmune diseases: evidence from animal models and in humans. Subcell Biochem 49: 325-350, 2008. 
8. Vaisar T, Pennathur S, Green PS, et al: Shotgun proteomics implicates protease inhibition and complement activation in the antiinflammatory properties of HDL. J Clin Invest 117: 746-756, 2007.

9. Bhakdi S, Lackner KJ, Han SR, Torzewski M and Husmann M: Beyond cholesterol: the enigma of atherosclerosis revisited. Thromb Haemost 91: 639-645, 2004.

10. Niculescu F and Rus H: Complement activation and atherosclerosis. Mol Immunol 36: 949-955, 1999.

11. Niculescu F, Badea T and Rus H: Sublytic C5b-9 induces proliferation of human aortic smooth muscle cells: role of mitogen activated protein kinase and phosphatidylinositol 3-kinase. Atherosclerosis 142: 47-56, 1999.

12. Fearon DT and Wong WW: Complement ligand-receptor interactions that mediate biological responses. Annu Rev Immunol 1: 243-271, 1983.

13. Walport MJ: Complement. First of two parts. N Engl J Med 344: 1058-1066, 2001.

14. Oudin S, Libyh MT, Goossens D, et al: A soluble recombinant multimeric anti-Rh(D) single-chain Fv/CR1 molecule restores the immune complex binding ability of CR1-deficient erythrocytes. J Immunol 164: 1505-1513, 2000.

15. Ripoche J and Sim RB: Loss of complement receptor type 1 (CR1) on ageing of erythrocytes. Studies of proteolytic release of the receptor. Biochem J 235: 815-821, 1986.

16. Herrera AH, Xiang L, Martin SG, Lewis J and Wilson JG: Analysis of complement receptor type 1 (CR1) expression on erythrocytes and of CR1 allelic markers in Caucasian and African American populations. Clin Immunol Immunopathol 87: 176-183, 1998.

17. Xiang L, Rundles JR, Hamilton DR and Wilson JG: Quantitative alleles of CR1: coding sequence analysis and comparison of haplotypes in two ethnic groups. J Immunol 163: 4939-4945, 1999.

18. Wilson AG, Symons JA, McDowell TL, McDevitt HO and Duff GW: Effects of a polymorphism in the human tumor necrosis factor alpha promoter on transcriptional activation. Proc Natl Acad Sci USA 94: 3195-3199, 1997.

19. Moulds JM, Brai M, Cohen J, et al: Reference typing report for complement receptor 1 (CR1). Exp Clin Immunogenet 15: 291-294, 1998.

20. Berliner J, Leitinger N, Watson A, Huber J, Fogelman A and Navab M: Oxidized lipids in atherogenesis: formation, destruction and action. Thromb Haemost 78: 195-199, 1997.

21. Libby P: Inflammation in atherosclerosis. Nature 420: 868-872, 2002.

22. Libby $\mathrm{P}$ and Galis ZS: Cytokines regulate genes involved in atherogenesis. Ann NY Acad Sci 748: 168-170, 1995.

23. Falcone C, Geroldi D, Buzzi MP, et al: The -374T/A RAGE polymorphism protects against future cardiac events in nondiabetic patients with coronary artery disease. Arch Med Res 39: 320-325, 2008 .

24. Nora JJ, Lortscher RH, Spangler RD, Nora AH and Kimberling WJ: Genetic-epidemiologic study of early-onset ischemic heart disease. Circulation 61: 503-508, 1980.

25. Libby P: Inflammatory mechanisms: the molecular basis of inflammation and disease. Nutr Rev 65: S140-S146, 2007.

26. Frostegard J, Ulfgren AK, Nyberg P, Hedin U, Swedenborg J, Andersson U and Hansson GK: Cytokine expression in advanced human atherosclerotic plaques: dominance of pro-inflammatory (Th1) and macrophage-stimulating cytokines. Atherosclerosis 145: 33-43, 1999.
27. Hansson GK: Inflammation, atherosclerosis, and coronary artery disease. N Engl J Med 352: 1685-1695, 2005

28. Mannik M, Arend MP, Hall AP and Gilliland BC: Studies on antigen-antibody complexes. I. Elimination of soluble complexes from rabbit circulation. J Exp Med 133: 713-739, 1971.

29. Qiao JH, Castellani LW, Fishbein MC and Lusis AJ: Immunecomplex-mediated vasculitis increases coronary artery lipid accumulation in autoimmune-prone MRL mice. Arterioscler Thromb 13: 932-943, 1993.

30. Beaumont JL: Auto-immune hyperlipidemia. An atherogenic metabolic disease of immune origin. Rev Eur Etud Clin Biol 15: 1037-1041, 1970.

31. Poston RN and Davies DF: Immunity and inflammation in the pathogenesis of atherosclerosis. A review. Atherosclerosis 19: 353-367, 1974

32. Spiera $H$ and Rothenberg RR: Myocardial infarction in four young patients with SLE. J Rheumatol 10: 464-466, 1983.

33. Nieminen MS, Mattila K and Valtonen V: Infection and inflammation as risk factors for myocardial infarction. Eur Heart J 14K: 12-16, 1993.

34. Grant PJ: The genetics of atherothrombotic disorders: a clinician's view. J Thromb Haemost 1: 1381-1390, 2003.

35. Goldbourt U and Neufeld HN: Genetics aspects of arteriosclerosis. Arteriosclerosis 6: 357-377, 1988.

36. Andreotti F, Porto I, Crea F and Maseri A: Inflammatory gene polymorphisms and ischaemic heart disease: review of population association studies. Heart 87: 107-112, 2002.

37. Torzewski M, Klouche M, Hock J, et al: Immunohistochemical demonstration of enzymatically modified human LDL and its colocalization with the terminal complement complex in the early atherosclerotic lesion. Arterioscler Thromb Vasc Biol 18: 369-378, 1998

38. Laine P, Pentikainen MO, Wurzner R, Penttilä A, Paavonen T, Meri S and Kovanen PT: Evidence for complement activation in ruptured coronary plaques in acute myocardial infarction. Am J Cardiol 90: 404-408, 2002.

39. Hammerschmidt DE, Greenberg CS, Yamada O, Craddock PR and Jacob HS: Cholesterol and atheroma lipids activate complement and stimulate granulocytes. A possible mechanism for amplification of ischemic injury in atherosclerotic states. J Lab Clin Med 98: 68-77, 1981.

40. Yasuda M, Takeuchi K, Hiruma M, et al: The complement system in ischemic heart disease. Circulation 81: 156-163, 1990.

41. Rother K, Till GO and Haensch GM: The Complement System. 2nd edition. Springer, Berlin, 1998.

42. Saito E, Fujioka T, Kanno H, et al: Complement receptors in atherosclerotic lesions. Artery 19: 47-62, 1992.

43. Zorzetto M, Ferrarotti I, Trisolini R, et al: Complement receptor 1 gene polymorphisms are associated with idiopathic pulmonary fibrosis. Am J Respir Crit Care Med 168: 330-334, 2003.

44. Vongpatanasin W: Management of hypertension in patients with coronary artery disease. Curr Hypertens Rep 10: 349-354, 2008.

45. Taddei S, Virdis A, Ghiadoni L, Salvetti G and Salvetti A: Endothelial dysfunction in hypertension. J Nephrol 13: 205-210, 2000 . 